\title{
Genetic inactivation of pleiotrophin but not midkine potentiates clonidine-induced alpha- 2 adrenergic-mediated analgesia
}

Marta Vicente-Rodríguez ${ }^{a}$, Carmen Pérez-García ${ }^{a}$, Esther Gramage a,b Gonzalo Herradón a*

${ }^{\text {a }}$ Pharmacology lab, Department of Pharmaceutical and Food Sciences. Facultad de Farmacia. Universidad CEU San Pablo, Cta. Boadilla Km. 5,300, 28668 Boadilla del Monte, Madrid, Spain.

${ }^{\mathrm{b}}$ Present address: Department of Ophthalmology and Visual Sciences, W. K. Kellogg Eye Center, University of Michigan, Ann Arbor, MI, USA

Marta Vicente-Rodríguez: marta.vicenterodriguez@ceu.es

Carmen Pérez-García: $\underline{\text { capegar@ } @ \text { ceu.es }}$

Esther Gramage: gramage@med.umich.edu

*Corresponding author:

Gonzalo Herradon, $\mathrm{PhD}$

Lab. Pharmacology and Toxicology

Universidad San Pablo CEU

Urb. Montepríncipe

Cta. Boadilla Km. 5,300

28668 Boadilla del Monte, Madrid, Spain.

Tel: 34-91-3724700

Fax: 34-91-3510475

e-mail: herradon@ceu.es 


\section{ABSTRACT}

Genetic deletion of the heparin-binding cytokines pleiotrophin (PTN) or midkine (MK) potentiates morphine-induced antinociceptive effects in animal models. Despite the known interactions between the opioid and noradrenergic systems in the control of pain, the possible roles of PTN and/or MK in analgesia induced by agonists of $\alpha_{2}$-adrenergic receptors remained to be studied. We have now tested the antinociceptive effects of the $\alpha_{2}-$ adrenergic receptor agonist clonidine in female PTN genetically deficient (PTN-/-), MK genetically deficient (MK-/-) and wild type (WT+/+) mice. We did not find differences among genotypes in the hot-plate test, an assay in which supraspinal and spinal mechanisms contribute to nociceptive responses, suggesting endogenous expression of PTN and MK is not key in the analgesia induced by clonidine in this test. In contrast, we found that clonidine-induced analgesia was significantly enhanced in PTN-/- mice compared to $\mathrm{MK}-/-$ and $\mathrm{WT}+/+$ mice in the tail-immersion test. Interestingly, the $\alpha_{2-}$ adrenergic antagonist yohimbine prevented clonidine-induced analgesia in the tail immersion test in all the 3 genotypes. The data suggest that the spinal antinociceptive effects caused by stimulation of $\alpha_{2}$-adrenoceptors are differentially regulated by endogenous expression of PTN.

Keywords: Tail flick, hot plate, yohimbine, pain, spinal, noradrenergic. 


\section{Introduction}

Midkine (MK) and Pleiotrophin (PTN) are heparin binding growth factors (Kadomatsu et al., 1988; Milner et al., 1989) that share over 50\% identity in amino acid sequence (Deuel et al., 2002). Both PTN and MK have been found to play important roles in the development of the nervous system through their actions on neuronal differentiation (Herradon and Ezquerra, 2009; Muramatsu, 2011; Gramage and Herradon, 2011). In addition, it has been hypothesized that both PTN and MK may play important roles on survival of different cell types and wound repair since both cytokines are upregulated at sites of injury and repair in inflammatory macrophages, microglia, dermal fibroblasts, endothelial cells and other cells (Blondet et al., 2005, Ezquerra et al., 2008, Gramage et al., 2010, Kikuchi-Horie et al., 2004, Martin et al., 2011; Mi et al., 2007, Sakakima et al., 2004a, 2004b, Yeh et al., 1998).

The role of MK in wound repair in the periphery has been linked to its potential actions in the guidance of neural axon regeneration in peripheral nervous system (Sakakima et al., 2009). This is supported by the delay in axonal regeneration uncovered in MK genetically deficient (MK-/-) mice with peripheral nerve injury, leading to the hypothesis that MK acts as a reparative neurotrophic factor in damaged peripheral nerves (Sakakima et al., 2009). That report significantly increased the relevance of previous findings demonstrating the consistent upregulation of MK expression levels after traumatic injury of the spinal cord and following sciatic nerve injury (Sakakima et al., 2004a, 2004b). Very interestingly, upregulation of the levels of the highly homologous cytokine PTN in the injured dorsal root ganglia (DRG) of rats with Chronic Constriction Injury (CCI) of the 
sciatic nerve correlates with faster recovery of neuropathic pain states (Ezquerra et al., 2008). Taking together, evidence suggests that these cytokines play a role in degeneration and regeneration after peripheral nerve injury and the recovery of subsequent chronic neuropathic pain state (Martin et al., 2011). Furthermore, we hypothesized that PTN and MK could play important roles not only in neurotrophic processes but in nociceptive transmission as well (Gramage and Herradon, 2010; Gramage et al., 2012). Accordingly, whereas nociceptive transmission seems to be unaffected in PTN genetically deficient (PTN-/-) and MK-/- mice in the hot plate test (Gramage and Herradon, 2010; Gramage et al., 2012), PTN-/- mice showed a delayed response to nociceptive stimulus in the tail-flick test compared to MK-/and wild type $(\mathrm{WT}+/+)$ mice, suggesting endogenous PTN modulates nociceptive transmission at the spinal level (Gramage and Herradon, 2010).

In the central nervous system, PTN and MK expression levels have been found to be significantly upregulated in different brain areas in humans and rodents after administration of different drugs including morphine (Ezquerra et al., 2007; Herradon et al., 2009). Interestingly, the antinociceptive effects of morphine are significantly enhanced in PTN-/and MK-/- mice (Gramage and Herradon, 2010; Gramage et al., 2012) suggesting that upregulation of these neurotrophic factors after morphine administration plays a role in the functional regulation of the pharmacological effects of morphine. It is interesting to note that descending noradrenergic inhibitory pathways in the control of pain contribute to opioidinduced analgesia (Herradon et al., 2003, 2008; Millan, 2002). However, the selective $\alpha_{2}-$ adrenergic antagonist yohimbine failed to prevent morphine-induced analgesia in acute pain models in MK-/-, PTN-/- and WT+/+ mice (Gramage et al., 2012). Although opioid $/ \alpha_{2}-$ adrenergic interactions do not seem to be prominent in morphine-induced analgesia in PTN- 
/- and MK-/- mice, the possibility of a differential analgesic effect of $\alpha_{2}$-adrenergic drugs depending on the presence of endogenous levels of PTN or MK should not be discarded especially when both PTN and MK have been shown to regulate the cathecolamine biosynthetic pathway in different contexts (Ezquerra et al., 2004; Ezquerra et al., 2006; Hida et al., 2007; Jung et al., 2004). To test this hypothesis, we aimed to study the analgesia induced by the $\alpha_{2}$-adrenergic agonist clonidine in PTN-/- and MK-/- compared to control, wild type mice. 


\section{Materials and Methods}

Midkine knockout (MK-/-) and PTN knockout (PTN-/-) mice were generated on a 129/Ola x C57BL/6J background by methods essentially identical to those previously described (Amet et al., 2001, Nakamura et al., 1998). The animals used in this study were 8-weeks old female MK-/-, PTN-/- mice and WT+/+ mice used as control. All the animals used in this study were maintained according to European Union Laboratory Animal Care Rules (86/609/ECC directive).

\subsection{Hot-plate test}

To assess nociceptive responses in PTN-/-, MK-/- and WT+/+ mice, we used the hotplate test following the procedure described previously (Gramage and Herradon, 2010). A metal hot-plate was maintained at $53 \pm 0.5^{\circ} \mathrm{C}$. The latency time to when the mouse first exhibited nocifensive behaviour (licked its hind paw or jumping) was determined. The cut-off time for the first sign of nocifensive behaviour was $75 \mathrm{~s}$.

To study the effect of clonidine on hot-plate response, saline $(10 \mathrm{ml} / \mathrm{kg})(\mathrm{n}=10$ 13/genotype), $0.25 \mathrm{mg} / \mathrm{kg}$ clonidine hydrochloride (Sigma, Madrid, Spain) (n = 7-9/genotype) or $0.50 \mathrm{mg} / \mathrm{kg}$ clonidine $(\mathrm{n}=10-14 /$ genotype $)$ were administered i.p. after testing the baseline response for the hot-plate maintained at $53 \pm 0.5^{\circ} \mathrm{C}$. To study the time course of the effect of clonidine, the hot-plate latency was recorded 25, 75 and 125 min after clonidine (or saline, as a control) injection. The doses of clonidine were selected because they were previously shown to be effective in similar experiments in mice (Blednov et al., 2003). Four independent experiments in different days were performed using balanced cohorts of animals per experimental group (genotype and treatment) every day. 


\subsection{Tail-immersion test}

\subsubsection{Clonidine-induced antinociceptive effects in PTN-/-, MK-/- and WT+/+ mice}

To assess spinal nociceptive responses in PTN-/-, MK-/- and WT+/+ mice, we used the tail-immersion test. To study the effect of clonidine on tail-immersion responses we used a bath maintained at a temperature of $55 \pm 0.5^{\circ} \mathrm{C}$. We used the same doses of clonidine tested in the hot plate assay $(0.25$ and $0.50 \mathrm{mg} / \mathrm{kg})$. Saline $(10 \mathrm{ml} / \mathrm{kg})$ or clonidine was administered i.p. after testing the baseline responses to the tail-immersion test using a cut-off latency of $15 \mathrm{~s}$ to prevent tissue damage. It is interesting to note that a small percentage of PTN-/- mice $(\sim 20 \%)$ were excluded of the pharmacological test because they reached the cut-off latency in baseline conditions which is in agreement with previous results from our group (Gramage et al., 2012). According to basal values, mice from every genotype were homogeneously distributed in salinetreated $(\mathrm{n}=8-11 /$ genotype $)$, clonidine $(0.25 \mathrm{mg} / \mathrm{kg})$-treated $(\mathrm{n}=12-14 / \mathrm{genotype})$ and clonidine (0.50 mg/kg)-treated groups $(\mathrm{n}=12-14 /$ genotype $)$. To study the time course of the antinociceptive effect of clonidine, the tail-flick latency was recorded 25, 50, 75 and 125 min after clonidine (or saline, as a control) injection. Three independent experiments in different days were performed using balanced cohorts of animals per experimental group (genotype and treatment) every day.

\subsubsection{Effects of Yohimbine on Clonidine-induced antinociceptive effects in PTN-/-, MK-/- and} $W T+/+$ mice

To test the possibility that clonidine-induced analgesia was mediated by $\alpha_{2}$-adrenergic mechanisms in PTN-/-, MK-/- and WT+/+ mice, we tested the effects of clonidine $(0.25 \mathrm{mg} / \mathrm{kg})$ in mice pretreated with the $\alpha_{2}$-adrenergic antagonist yohimbine (Sigma, Madrid, Spain). For this 
purpose, after determination of basal responses, mice were injected (i.p.) with yohimbine (1.40 $\mathrm{mg} / \mathrm{kg})$ or saline $(10 \mathrm{ml} / \mathrm{kg}$; control $) 10$ minutes before clonidine $(0.25 \mathrm{mg} / \mathrm{kg})$ or saline $(10$ $\mathrm{ml} / \mathrm{kg}$; control) administration. As a result, we obtained four experimental groups: saline+saline $(n=7-10 /$ genotype $)$, saline+clonidine $(n=8-10 /$ genotype $)$, yohimbine+saline $(n=6-9 /$ genotype $)$ and yohimbine+clonidine ( $\mathrm{n}=7-8 /$ genotype). The tail-flick latency was recorded $25,50,75$ and 125 min after clonidine (or saline) injection. Three independent experiments in different days were performed using balanced cohorts of animals per experimental group (genotype and treatment) every day.

\subsection{Statistical Analysis}

The statistical significance of changes within the same treatment was determined by 2way repeated-measures ANOVA considering as factors the genotype and the 4 or 5 time points after injection depending on the experimental model (time-curse curves). Bonferroni's post hoc tests were used to detect the sources of group differences revealed by the ANOVAs.

For subsequent analysis, latencies were converted to percentages of maximal possible effect (\%MPE), a way of expressing the absolute latencies relative to baseline ( $0 \% \mathrm{MPE})$ and to cut-off time (100\% MPE), according to the formula:

$\% \mathrm{MPE}=($ test - baseline $) /($ cutoff - baseline $) \times 100$

In this manner, \%MPE data were analyzed within each time point by 2-way ANOVA considering as factors genotype and treatment. The factor time was also analyzed as a withinsubjects factor. Bonferroni's post hoc tests were used to detect the sources of group differences revealed by the ANOVAs. 
Area under the curve (AUC) values obtained from PTN-/-, MK-/- and WT+/+ mice were analyzed using student's t test when two treatments were compared within the same genotype. In all analyses, $\mathrm{P}<0.05$ was considered statistically significant. 


\section{Results}

\subsection{Hot-plate test}

In the studies directed to assess clonidine-induced antinociceptive effects in the hot-plate maintained at $53{ }^{\circ} \mathrm{C}$, we first analyzed together basal values of mice from the three genotypes used in all experiments performed $(n=24-32 /$ genotype $)$. The latency to the first sign of nocifensive behaviour in mice of all genotypes was found to be similar in the hot-plate test $(\mathrm{WT}+/+=31.9 \pm 2.0 \mathrm{~s} ; \mathrm{PTN}-/-=25.2 \pm 2.2 \mathrm{~s} ; \mathrm{MK}-/-=29.1 \pm 1.6 \mathrm{~s})$.

Analysis of the latency values induced by clonidine $(0.25 \mathrm{mg} / \mathrm{kg}$ and $0.50 \mathrm{mg} / \mathrm{kg})$ revealed a robust antinociceptive effect significantly dependent on time whereas ANOVA did not reveal significant genotypic differences (Fig. 1A,B). Interestingly, analysis of \%MPE data show that $0.50 \mathrm{mg} / \mathrm{kg}$ clonidine induced similar antinociceptive effects among the different genotypes at all times after administration of the drug (Fig. 1C-E), with the only exception of PTN-/- mice tested 75 min after clonidine administration which show a significant increase of \%MPE in clonidine $(0.50 \mathrm{mg} / \mathrm{kg})$-treated mice compared to saline-treated mice. In addition, we found significant antinociceptive effects of $0.25 \mathrm{mg} / \mathrm{kg}$ clonidine compared to saline administration in $\mathrm{WT}+/+$ mice (25 and $75 \mathrm{~min}$ ) and MK-/- mice (25 min) (Figs. 1C-E). As observed in the time-response curve (Fig. 1A), \%MPE of $0.25 \mathrm{mg} / \mathrm{kg}$ clonidine tended to be lower in PTN-/- mice 25 and 75 minutes after clonidine administration (Fig. 1C,D) although statistical differences between genotypes were not achieved. Nociceptive responses after saline administrations showed a clear trend to increase in each time point but genotypic differences were lacking at all time points (Figs. 1C-E). A significant effect of time, analyzed as a withinsubjects factor, was detected in all treatments. 


\subsection{Tail-immersion test}

\subsubsection{Clonidine-induced antinociceptive effects in PTN-/-, MK-/- and WT+/+mice}

Taking together the basal values of all mice from the three genotypes used in the studies assessing clonidine effects (except the ones that reached the cut-off values in basal conditions which were $20 \%$ of the PTN-/- mice used), a trend to show higher latency values in the tail immersion test was observed in PTN-/- mice $(4.5 \pm 0.3 \mathrm{~s})$ compared to WT+/+ $(3.9 \pm 0.2 \mathrm{~s})$ and MK-/- mice (3.8 $\pm 0.3 \mathrm{~s})$. Analysis of the studies using $0.25 \mathrm{mg} / \mathrm{kg}$ clonidine (Fig. $2 \mathrm{~A})$ revealed a significant interaction time $\mathrm{x}$ genotype $(\mathrm{F}(8,144)=3.100, \mathrm{P}<0.01)$. Bonferroni's post hoc tests confirmed a significantly enhanced antinociceptive effect of $0.25 \mathrm{mg} / \mathrm{kg}$ clonidine in PTN-/mice compared to $\mathrm{WT}+/+$ and $\mathrm{MK}-/-$ mice. The 2-way repeated measures ANOVA revealed a significant interaction time $x$ genotype $(F(8,144)=2.136, P<0.05)$ in the experiments performed to test the antinociceptive effect of the highest dose of clonidine $(0.50 \mathrm{mg} / \mathrm{kg})$ used in our studies (Fig. 2B). Although $0.50 \mathrm{mg} / \mathrm{kg}$ clonidine tended to cause greater antinociceptive effects in PTN-/- mice, Bonferroni's post hoc tests did not reveal differences between genotypes. However, analysis of \%MPE data show that $0.25 \mathrm{mg} / \mathrm{kg}$ clonidine induced significantly enhanced antinociceptive effects in PTN-/- mice compared to $\mathrm{WT}+/+$ and $\mathrm{MK}-/-$ mice 25 min (Fig. 2C), $50 \mathrm{~min}$ (Fig. 2D) and $75 \mathrm{~min}$ (Fig. 2E) after administration of the drug. In addition, we found significantly enhanced antinociceptive effects of $0.50 \mathrm{mg} / \mathrm{kg}$ clonidine in PTN-/- mice compared to control WT+/+ mice 50 min (Fig. 2D) and 75 min (Fig. 2E) after administration of clonidine. No significant differences between genotypes were obtained 125 min after clonidine administration (Fig. 2F). Finally, nociceptive responses after saline administrations tended to manifest faster than in basal conditions in the different measures performed at different time points as represent \%MPE values below baseline (0\%) but genotypic differences were lacking at 
all time points (Figs. 2C-F). As in the case of the hot-plate test, a significant effect of time, analyzed as a within-subjects factor, was detected in all treatments.

\subsubsection{Effects of Yohimbine on Clonidine-induced antinociceptive effects in PTN-/-, MK-/- and} WT+/+ mice.

Confirming the trend observed in the tail immersion studies summarized above and previous evidence (Gramage et al., 2012), one-way ANOVA of baseline responses ( $\mathrm{F}=9.265$, $\mathrm{P}<0.001$ ) of mice included in the 4 experimental groups (saline+saline, saline+clonidine, yohimbine+saline, yohimbine+clonidine) revealed that basal latencies of PTN-/- mice $(4.4 \pm$ $0.3 \mathrm{~s})$ were significantly increased by $1-2 \mathrm{~s}$ compared to $\mathrm{WT}+/+(3.3 \pm 0.2 \mathrm{~s})$ and $\mathrm{MK}-/-$ mice $(3.1$ $\pm 0.2 \mathrm{~s})$. Mice from the three genotypes were accordingly distributed in the four experimental groups in order to minimize baseline differences between groups.

Two-way repeated-measures ANOVA did not reveal significant effects of pretreatment with the $\alpha_{2}$-adrenergic antagonist yohimbine $(1.40 \mathrm{mg} / \mathrm{kg})$ on clonidine-induced analgesia in WT+/+ mice (Fig. 3A). However, AUC values from yohimbine+clonidine treated WT+/+ mice were significantly lower than those of saline+clonidine treated $\mathrm{WT}+/+$ mice (Fig. 3D). In this case, the modest antinociceptive effects caused by clonidine in saline-pretreated WT+/+ mice could mask the antagonistic effect of yohimbine. Interestingly, pretreatment with yohimbine (1.40 mg/kg) effectively blocked clonidine-induced analgesia in PTN-/- (Fig. 3B) and MK-/mice (Fig. 3C). ANOVA revealed in both genotypes a significant interaction time $\mathrm{x}$ treatment (PTN-/-, $\mathrm{F}(4,56)=3.125, \mathrm{P}<0.05 ; \mathrm{MK}-/-, \mathrm{F}(4,52)=6.195, \mathrm{P}<0.0001)$. In confirmation, AUC values were significantly decreased in yohimbine-pretreated, clonidine-treated PTN-/- (Fig. 3E) and MK-/- mice (Fig. 3F) compared to saline-pretreated mice. In control studies, pretreatment with saline before saline injection did not cause changes in the nociceptive responses of mice 
from the three genotypes (Fig. 3G-I). Animals of the three genotypes pretreated with yohimbine and treated with saline showed modest differences compared to those only treated with saline in the tail-immersion test (Figs. 3G-I). Although ANOVA detected a significant effect of the treatment in PTN-/- and in MK-/- mice, the analysis did not reveal a significant interaction between factors (time $\mathrm{x}$ treatment) in none of the three genotypes. 


\section{Discussion}

In the present study, we uncover for the first time that endogenous expression of PTN, but not of MK, regulates clonidine-induced analgesia at the spinal level. We found that the antinociceptive effect of clonidine was potent and similar in MK-/-, PTN-/- and WT+/+ mice in the hot-plate test. Since the behaviors tested in the hot plate test are complex and require not only spinal but supraspinal sensory processing, the data strongly suggest that clonidineinduced analgesia at the supraspinal level is not affected by the endogenous levels of PTN or MK. Taking together the basal responses of all the three genotypes in all experiments performed in the tail immersion test, higher latencies to exert the nocifensive behavior (tail flick) were observed in PTN-/- mice compared to MK-/- and WT+/+ mice confirming previous evidence from our group (Gramage et al., 2012). After appropriate distribution of PTN-/- mice according to their basal values in order to minimize baseline differences between the different experimental groups, we found that both doses of clonidine tested $(0.25$ and $0.50 \mathrm{mg} / \mathrm{kg})$ caused enhanced antinociceptive effects in PTN-/- compared to MK-/- and WT+/+ mice. Interestingly, a lower dose of clonidine $(0.25 \mathrm{mg} / \mathrm{kg})$ known to cause moderate antinociceptive effects in the tail flick test showed exacerbated analgesic effects in PTN-/- mice compared to the other two genotypes 25, 50 and 75 min after clonidine administration.

Since the $\alpha_{2}$-adrenergic antagonist yohimbine blocked clonidine antinociceptive effects independently of the analgesic potency reached in each of the genotypes, the data suggest that the spinal antinociceptive effects caused by stimulation of $\alpha_{2}$-adrenoceptors is differentially regulated by endogenous expression of PTN. There is evidence that several pharmacologic actions of $\alpha_{2}$-adrenergic receptor agonists are mediated via activation of not only $\alpha_{2}$-adrenergic receptors but also by imidazoline receptors (Millan, 2002). However, our data show that the antinociceptive effects of clonidine are efficiently blocked by yohimbine suggesting clonidine- 
induced analgesia in the tail flick test is mediated by $\alpha_{2}$-adrenergic receptors. Our observations are consistent with previous reports showing that yohimbine selectively reverses the topical antinociceptive effects of clonidine (Dogrul and Uzbay, 2004) and, more importantly, that yohimbine prevents clonidine-induced antinociceptive effects in the tail flick test (Dogrul et al., 2006).

It has been previously shown that inhibitors of serine/threonine protein phosphatases antagonize the antinociception induced by agonists of $\alpha_{2}$-adrenergic receptors such as clonidine (Moncada et al., 2005). However, to the best of our knowledge, a connection between specific protein tyrosine phosphatases and the analgesic effects of agonists of $\alpha_{2}$ adrenergic receptors has not been suggested before. Very interestingly, PTN is known to bind the Receptor Protein Tyrosine Phosphatase (RPTP) $\beta / \zeta$ (Meng et al., 2000), disrupting as a result its phosphatase activity. Thus, PTN induces significant increases in the tyrosine phosphorylation levels of the different substrates of RPTP $\beta / \zeta$ identified so far, $\beta$-catenin (Meng et al., 2000), $\beta$-adducin (Pariser et al., 2005a,b), Fyn (Pariser et al., 2005c), p190 RhoGAP and membrane-associated guanylate kinase, WW, and PDZ domain containing 1 (Fukada et al., 2005), anaplastic lymphoma kinase (ALK) (Perez-Pinera et al., 2007) and GIT1/Cat-1 (Kawachi et al., 2001). The well-established mechanism of action of PTN supports the hypothesis that inhibition of the tyrosine phosphatase activity of RPTP $\beta / \zeta$ by endogenous PTN in WT+/+ mice may limit clonidine-induced antinociceptive effects. In contrast, the unchecked tyrosine phosphatase activity of RPTP $\beta / \zeta$ in PTN-/- mice may potentially underlie the enhanced antinociceptive effects of clonidine in animals lacking endogenous PTN. It is important to note that $\mathrm{MK}$ is also known to bind RPTP $\beta / \zeta$ and to inhibit its tyrosine phosphatase activity (Sakaguchi et al., 2003). However, in contrast to PTN-/- mice, clonidineinduced antinociceptive effects are unaffected in MK-/- mice compared to WT+/+ mice. 
Despite these differences between PTN-/- and MK-/- mice, the hypothesis that tyrosine phosphatase activity of RPTP $\beta / \zeta$ in PTN-/- mice may underlie the enhanced antinociceptive effects of clonidine in this genotype should not be discarded. It is very important to note that MK-/- mice show upregulated levels of expression of PTN in spinal cord and DRG, probably as part of compensatory mechanisms (Herradon et al., 2005). In contrast, PTN-/- mice do not show upregulation of MK levels (Herradon et al., 2005), suggesting the tyrosine phosphatase activity of RPTP $\beta / \zeta$ is limited by enhanced PTN levels in spinal cord and DRG, relevant areas in the tail immersion test, of MK-/- mice whereas remains efficient in PTN-/- mice. On the other hand, the reason why the increased antinociceptive effects of clonidine in PTN-/- mice are observed at the spinal, but not the supraspinal, level remains to be clarified. However, evidence supports further studies to dissect a possible differential contribution of the phosphatase activity of RPTP $\beta / \zeta$ to the balanced kinase-phosphatase systems at the spinal and the supraspinal level.

The data presented here suggest that PTN but not MK limits clonidine-induced analgesia, suggesting that exogenous administration of clonidine may induce the expression of PTN but not MK. Whether or not clonidine modulates the levels of expression of PTN and/or MK remains to be studied and it is a significant limitation of the present study. Another limitation of this study is that we have not tested the effects of exogenous administration of PTN or MK on clonidine-induced antinociceptive effects. Given the nature of these proteins, i.t. administration of these cytokines would be required to demonstrate a possible regulation of clonidine effects at the spinal level. However, to the best of our knowledge, there are not previous reports in the literature using this type of route of administration with these cytokines in any experimental context. Thus, it is difficult to anticipate the range of doses of these 
proteins to be used and preliminary experiments should be performed to construct adequate dose-response curves.

In summary, the data presented here suggest previously unexpected roles of endogenous PTN in the modulation of clonidine-induced analgesia at the spinal level through activation of $\alpha_{2}$-adrenergic receptors. Collectively, these data suggest for the first time differences in the modulatory roles of the otherwise functionally redundant cytokines PTN and MK on the antinociceptive effects of clonidine.

\section{Acknowledgements:}

This work has been supported in part by grant SAF2009-08136 from Ministerio de Ciencia e Innovación of Spain. Marta Vicente-Rodríguez is supported by fellowship from USP-CEU. Esther Gramage was supported by fellowship AP2008-00726 from Ministerio de Ciencia e Innovación of Spain. 


\section{References}

Amet LE, Lauri SE, Hienola A, Croll SD, Lu Y, Levorse JM et al. Enhanced hippocampal long-term potentiation in mice lacking heparin-binding growth-associated molecule. Mol Cell Neurosci 2001; 17(6):1014-24.

Blednov YA, Stoffel M, Alva H, Harris RA. A pervasive mechanism for analgesia: activation of GIRK2 channels. Proc Natl Acad Sci U S A. 2003; 100(1):277-82.

Blondet B, Carpentier G, Lafdil F, Courty J. Pleiotrophin cellular localization in nerve regeneration after peripheral nerve injury. J Histochem Cytochem 2005; 53(8): 9717.

Deuel TF, Zhang N, Yeh HJ, Silos-Santiago I, Wang ZY. Pleiotrophin: a cytokine with diverse functions and a novel signaling pathway. Arch Biochem Biophys 2002; 397(2): 162-71.

Dogrul A, Uzbay IT. Topical clonidine antinociception. Pain 2004; 111(3):385-91.

Ezquerra L, Alguacil LF, Nguyen T, Deuel TF, Silos-Santiago I, Herradon G. Different pattern of pleiotrophin and midkine expression in neuropathic pain: correlation between changes in pleiotrophin gene expression and rat strain differences in neuropathic pain. Growth Factors 2008; 26(1):44-8.

Ezquerra L, Herradón G, Nguyen T, Vogt TF, Bronson R, Silos-Santiago I, Deuel TF. Pleiotrophin is a major regulator of the catecholamine biosynthesis pathway in mouse aorta. Biochem Biophys Res Commun 2004; 323(2):512-7.

Ezquerra L, Herradón G, Bronson R, Silos-Santiago I, Deuel TF. Midkine is a potent regulator of the catecholamine biosynthesis pathway in mouse aorta. Life Sci 2006; 79(11):1049-55. 
Ezquerra L, Perez-Garcia C, Garrido E, Diez-Fernandez C, Deuel TF, Alguacil LF et al. Morphine and yohimbine regulate midkine gene expression in the rat hippocampus. Eur J Pharmacol 2007; 557(2-3): 147-50.

Fukada M, Kawachi H, Fujikawa A, Noda M .Yeast substrate-trapping system for isolating substrates of protein tyrosine phosphatases: Isolation of substrates for protein tyrosine phosphatase receptor type z. Methods 2005; 35(1): 54-63.

Gramage E, Herradon G. Genetic deletion of pleiotrophin leads to disruption of spinal nociceptive transmission: Evidence for pleiotrophin modulation of morphineinduced analgesia. Eur J Pharmacol 2010; 647(1-3):97-102.

Gramage E, Rossi L, Granado N, Moratalla R, Herradon G. Genetic inactivation of Pleiotrophin triggers amphetamine-induced cell loss in the substantia nigra and enhances amphetamine neurotoxicity in the striatum. Neuroscience $2010 ; 170(1)$ : 308-16.

Gramage E, Herradon G. Connecting Parkinson's disease and drug addiction: common players reveal unexpected disease connections and novel therapeutic approaches. Curr Pharm Des 2011; 17(5):449-61.

Gramage E, Martín, YB, Herradon G. The heparin binding growth factors midkine and pleiotrophin regulate the antinociceptive effects of morphine through $\alpha(2)$ adrenergic independent mechanisms. Pharmacol Biochem Behav 2012; 101(3):38793.

Herradon G, Ezquerra L, Nguyen T, Wang C, Siso A, Franklin B, Dilorenzo L, Rossenfeld J, Silos-Santiago I, Alguacil LF. Noradrenergic and opioidergic alterations in neuropathy in different rat strains. Neurosci Lett 2008; 438(2):186-9. 
Herradon G, Ezquerra L. Blocking receptor protein tyrosine phosphatase beta/zeta: a potential therapeutic strategy for Parkinson's disease. Curr Med Chem 2009; 16(25): 3322-9.

Herradon G, Ezquerra L, Gramage E, Alguacil LF. Targeting the pleiotrophin/receptor protein tyrosine phosphatase beta/zeta signaling pathway to limit neurotoxicity induced by drug abuse. Mini Rev Med Chem 2009; 9(4): 440-7.

Herradon G, Ezquerra L, Nguyen T, Silos-Santiago I, Deuel TF. Midkine regulates pleiotrophin organ-specific gene expression: evidence for transcriptional regulation and functional redundancy within the pleiotrophin/midkine developmental gene family. Biochem Biophys Res Commun 2005; 333(3): 714-21.

Herradón G, Morales L, Pérez-García C, Alguacil LF. The contribution of alpha2adrenoceptor and opioid receptor mechanisms to antinociception differs in Lewis and Fischer 344 rats. Eur J Pharmacol 2003; 465(3):251-6.

Hida H, Masuda T, Sato T, Kim TS, Misumi S, Nishino H. Pleiotrophin promotes functional recovery after neural transplantation in rats. Neuroreport 2007; 18(2): $179-83$.

Jung CG, Hida H, Nakahira K, Ikenaka K, Kim HJ, Nishino H. Pleiotrophin mRNA is highly expressed in neural stem (progenitor) cells of mouse ventral mesencephalon and the product promotes production of dopaminergic neurons from embryonic stem cell-derived nestin-positive cells. Faseb J 2004; 18(11): 1237-39.

Kadomatsu K, Tomomura M, Muramatsu T. cDNA cloning and sequencing of a new gene intensely expressed in early differentiation stages of embryonal carcinoma cells and in mid-gestation period of mouse embryogenesis. Biochem Biophys Res Commun 1988; 151(3): 1312-18. 
Kawachi H, Fujikawa A, Maeda N, Noda M. Identification of GIT1/Cat-1 as a substrate molecule of protein tyrosine phosphatase zeta /beta by the yeast substrate-trapping system. Proc Natl Acad Sci U S A 2001; 98(12): 6593-8.

Kikuchi-Horie K, Kawakami E, Kamata M, Wada M, Hu JG, Nakagawa H et al. Distinctive expression of midkine in the repair period of rat brain during neurogenesis: immunohistochemical and immunoelectron microscopic observations. J Neurosci Res 2004; 75(5): 678-87.

Martín YB, Herradón G, Ezquerra L. Uncovering new pharmacological targets to treat neuropathic pain by understanding how the organism reacts to nerve injury. Curr Pharm Des 2011; 17(5):434-48.

Meng K, Rodriguez-Pena A, Dimitrov T, Chen W, Yamin M, Noda M et al. Pleiotrophin signals increased tyrosine phosphorylation of beta beta-catenin through inactivation of the intrinsic catalytic activity of the receptor-type protein tyrosine phosphatase beta/zeta. Proc Natl Acad Sci U S A 2000; 97(6): 2603-8.

Mi R, Chen W, Hoke A. Pleiotrophin is a neurotrophic factor for spinal motor neurons. Proc Natl Acad Sci U S A 2007; 104(11): 4664-4669.

Millan MJ. Descending control of pain. Prog Neurobiol 2002; 66(6):355-474.

Milner PG, Li YS, Hoffman RM, Kodner CM, Siegel NR, Deuel TF. A novel 17 kD heparin-binding growth factor (HBGF-8) in bovine uterus: purification and $\mathrm{N}$ terminal amino acid sequence. Biochem Biophys Res Commun 1989; 165(3): 1096103.

Moncada A, Cendán CM, Baeyens JM, Del Pozo E. Inhibitors of serine/threonine protein phosphatases antagonize the antinociception induced by agonists of alpha 2 
adrenoceptors and $\mathrm{GABAB}$ but not kappa-opioid receptors in the tail flick test in mice. Pain 2005;114(1-2):212-20.

Muramatsu T. Midkine: a promising molecule for drug development to treat diseases of the central nervous system. Curr Pharm Des 2011; 17(5):410-23.

Nakamura E, Kadomatsu K, Yuasa S, Muramatsu H, Mamiya T, Nabeshima T et al. Disruption of the midkine gene (Mdk) resulted in altered expression of a calcium binding protein in the hippocampus of infant mice and their abnormal behaviour. Genes Cells 1998; 3(12): 811-22.

Pariser H, Herradon G, Ezquerra L, Perez-Pinera P, Deuel TF. Pleiotrophin regulates serine phosphorylation and the cellular distribution of beta-adducin through activation of protein kinase C. Proc Natl Acad Sci U S A 2005a; 102(35): 12407-12.

Pariser H, Perez-Pinera P, Ezquerra L, Herradon G, Deuel TF. Pleiotrophin stimulates tyrosine phosphorylation of beta-adducin through inactivation of the transmembrane receptor protein tyrosine phosphatase beta/zeta. Biochem Biophys Res Commun 2005b; 335(1): 232-9.

Pariser H, Ezquerra L, Herradon G, Perez-Pinera P, Deuel TF. Fyn is a downstream target of the pleiotrophin/receptor protein tyrosine phosphatase beta/zeta-signaling pathway: regulation of tyrosine phosphorylation of Fyn by pleiotrophin. Biochem Biophys Res Commun 2005c; 332(3): 664-9.

Perez-Pinera P, Zhang W, Chang Y, Vega JA, Deuel TF. Anaplastic lymphoma kinase is activated through the pleiotrophin/receptor protein-tyrosine phosphatase beta/zeta signaling pathway: an alternative mechanism of receptor tyrosine kinase activation. J Biol Chem 2007; 282(39):28683-90. 
Sakaguchi N, Muramatsu H, Ichihara-Tanaka K, Maeda N, Noda M, Yamamoto T et al. Receptor-type protein tyrosine phosphatase zeta as a component of the signaling receptor complex for midkine-dependent survival of embryonic neurons. Neurosci Res 2003; 45(2): 219-24.

Sakakima H, Yoshida Y, Kadomatsu K, Yuzawa Y, Matsuo S, Muramatsu T. Midkine expression in rat spinal motor neurons following sciatic nerve injury. Brain Res Dev Brain Res 2004a; 153(2): 251-60.

Sakakima H, Yoshida Y, Muramatsu T, Yone K, Goto M, Ijiri Ket al. Traumatic injuryinduced midkine expression in the adult rat spinal cord during the early stage. $\mathrm{J}$ Neurotrauma 2004b; 21(4): 471-7.

Sakakima H, Yoshida Y, Yamazaki Y, Matsuda F, Ikutomo M, Ijiri K et al. Disruption of the midkine gene (Mdk) delays degeneration and regeneration in injured peripheral nerve. J Neurosci Res 2009; 87(13): 2908-15.

Yeh HJ, He YY, Xu J, Hsu CY, Deuel TF. Upregulation of pleiotrophin gene expression in developing microvasculature, macrophages, and astrocytes after acute ischemic brain injury. J Neurosci 1998; 18(10): 3699-707. 


\section{FIGURE LEGENDS}

Fig. 1. Comparison of antinociceptive effects of clonidine in WT+/+, PTN-/- and MK-/mice in the hot-plate test. Results from hot-plate maintained at $53{ }^{\circ} \mathrm{C}$ are shown. The analgesic effect of $0.25 \mathrm{mg} / \mathrm{kg}$ clonidine (A) and $0.50 \mathrm{mg} / \mathrm{kg}$ clonidine (B) on the hot-plate test are shown as a function of time. The percentage of MPE induced by saline (control) and clonidine $(0.25$ and $0.50 \mathrm{mg} / \mathrm{kg}$ ) in all genotypes $25 \mathrm{~min}(\mathrm{C}), 75 \mathrm{~min}(\mathrm{D})$ and $125 \mathrm{~min}$ (E) after clonidine administration is represented. Data show mean \pm SEM. $* \mathrm{P}<0.05$ vs. saline, $* * \mathrm{P}<0.01$ vs. saline, $* * * \mathrm{P}<0.001$ vs. saline.

Fig. 2. Comparison of antinociceptive effects of clonidine in WT+/+, PTN-/- and MK-/mice in the tail immersion test. Results from tail-immersion test using a bath maintained at $55^{\circ} \mathrm{C}$ are shown. The analgesic effect of $0.25 \mathrm{mg} / \mathrm{kg}$ clonidine (A) and $0.50 \mathrm{mg} / \mathrm{kg}$ clonidine (B) on the tail immersion test are shown as a function of time. The percentage of MPE induced by saline (control) and clonidine $(0.25$ and $0.50 \mathrm{mg} / \mathrm{kg}$ ) in all genotypes 25 $\min (\mathrm{C}), 50 \mathrm{~min}(\mathrm{D}), 75 \mathrm{~min}(\mathrm{E})$ and $125 \mathrm{~min}(\mathrm{~F})$ after clonidine administration is represented. Data show mean \pm SEM. $* \mathrm{P}<0.05$ vs. saline, $* * \mathrm{P}<0.01$ vs. saline, $* * * \mathrm{P}<$ 0.001 vs. saline. \# $\mathrm{P}<0.05$ vs. $\mathrm{WT}+/+. \$ \mathrm{P}<0.05$ vs. MK-/-.

Fig. 3. Comparison of antinociceptive effects of clonidine in the tail immersion test in WT+/+, PTN-/- and MK-/- mice pretreated with yohimbine. Analgesic effects of clonidine $(0.25 \mathrm{mg} / \mathrm{kg})$ on the tail-immersion test are shown as a function of time in $\mathrm{WT}+/+$ (A), PTN-/- (B) and MK-/- (C) mice pretreated with yohimbine (1.40 mg/kg). Area under the curve (AUC) values for WT+/+ (D), PTN-/- (E) and MK-/- (F) mice pretreated with 
saline and treated with clonidine $(0.25 \mathrm{mg} / \mathrm{kg})$ are also compared. In control studies, effects of saline are also shown as a function of time in $\mathrm{WT}+/+(\mathrm{G}), \mathrm{PTN}-/-(\mathrm{H})$ and $\mathrm{MK}-/-(\mathrm{I})$ mice pretreated with yohimbine $(1.40 \mathrm{mg} / \mathrm{kg})$. Sal+Clo $=$ Pretreatment with saline, treatment with clonidine $(0.25 \mathrm{mg} / \mathrm{kg})$. Yoh+Clo $=$ Pretreatment with yohimbine $(1.40$ $\mathrm{mg} / \mathrm{kg})$, treatment with clonidine $(0.25 \mathrm{mg} / \mathrm{kg})$. Data show mean $\pm \mathrm{SEM} . * \mathrm{P}<0.05$ vs. sal+clo. 